\title{
A study of the agricultural design in the U.S. aid period (1951-1965)
}

\author{
Chu-Yu Sun / National Kaohsiung Normal University / Kaohsiung / Taiwan
}

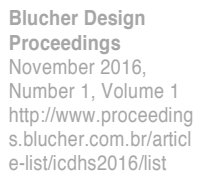

\begin{abstract}
This paper aims to discuss the propaganda for the general people in the early agricultural society in the U.S. Aid period (1951-1965). The text adopted was the agriculture publications by Joint Commission on Rural Reconstruction (JCRR), Harvest Farm Magazine and Four-H Association, etc., which were funded by U.S. Aid.

The era between 1950-1960 saw the stable growth of agricultural economy. The peasants' levels of education during this time were improved along with the improvement of economy. From the investigation of Taiwan's early agricultural society from the publications concerning agricultural education, the project would discover that, while the government strengthened its promotion of the knowledge of how to farm and raise, propaganda became the common graphic medium for promoting and spreading agricultural education through cartoon and illustration.
\end{abstract}

\section{Keywords}

Taiwan, U.S. Aid period, agriculture design, visual culture

\section{Introduction}

The fifties and sixties were a period of land reform and agricultural economic development in Taiwan. While Taiwan has witnessed certain accomplishments in the area of political economic research on the period of U.S. aid, few studies have examined this period from the perspective of art and design (Lai, Y. Z., 1993). In particular, there has been little monographic research concerning the theme of agricultural imagery during the period of U.S. aid. Taiwan still had critical implications for the global military situation even after the end of World War II. Externally, Taiwan was protected by the promise of U.S. military cooperation, while internally it was receiving funding in the form of U.S. economic aid. In addition, the Kuomintang (KMT) government undertook land reform (1949 1953) and economic development (1953 1965) (Yuan, Y. S., 1998). At the end of the period of U.S. aid Taiwan had gradually transformed itself from a poor country with inadequate food resources to one with a stable foreign currency exchange (Tsai, S. S., 2015). During this period, its people were exposed to the culture and popular trends of the world's powerful countries, as well as major international events.

This study undertakes a literary and historical discussion of design during this period, with the sociology of art as its methodology, and takes the three criterion of "representativeness," "importance," and "preciousness" in selecting materials to verify the inseparable relationship between art and society during this period, in addition to performing an analysis of the imagery and visual styles of artistic design, and building a visual culture for Taiwanese rural society during the period of U.S. aid. It is hoped that this study will foster a deep sense of nostalgia for the design content of this period.

\section{Literature review \\ Post-Colonial Land Renewal}

The Taiwanese provincial government clearly stipulated authority and responsibility in the relationship between landlord and sharecropper through the reduction of rents for farmlands in all cities and counties to $37.5 \%$ of production in May, 1949, which ensured the rights of sharecroppers and improved their livelihood. In January, 1953 the government implemented its land-to-the-tiller program, which expropriated the excess land of landlords in order to foster self-sufficiency in land-owning farmers. From 1949 to 1953 the KMT government reconstructed the production 
and distribution structure of the post-World War II economic order through the $37.5 \%$ measure, the releasing of public land, and the land-to-the-tiller policy(Taiwan Provincial Government, 1971). It was able to implement these policies based Sun Yat-sen's three people's principles, and those of the livelihood of the people and equal distribution of land in particular, within short period of several years. As a result of more equitable land distribution resulting from reforms, the traditional relationship between landlord and sharecropper gradually disappeared. The new landowning farm households, economically independent individuals with social equality, arose as a result (Huang, C. J., 1991; Han, S. H., 2006).

\section{Sino-American Cooperation in the Period of U.S. Aid}

U.S. aid consisted of military and general economic assistance. After World War II the world situation was rapidly transformed, and two camps emerged, the free world led by the United States and the communist bloc. The United States aided to the KMT government in the second half of 1951 . This officially commenced the beginning of the period of U.S. aid, which lasted until June 30, 1965 when the United States announced its discontinuation. The United States and the ROC signed military aid agreements on February 10, 1951, the "Common Defense Agreement," and another on December 3, 1954 entitled the "Sino-American Mutual Defense Treaty." The economic and military agreements signed with the United States assured Taiwan's economic security internally and military stability externally. As such, it had an inseparable relationship with respect to the solidification of defense capabilities, a nation's top priority, as well as economic development during the period of U.S. aid from 1951 to 1965, which had a deep and long-lasting impact (Liu, Z. W., 2012).



Fig. 1: Fertilization promotion poster

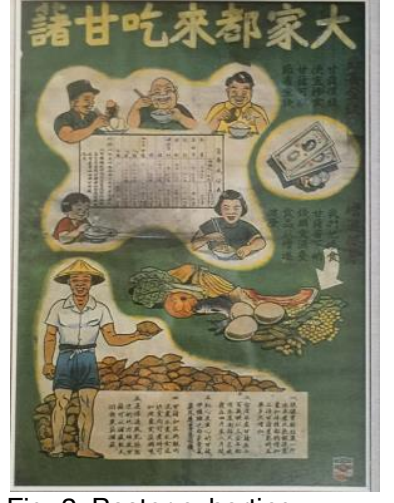

Fig. 2: Poster exhorting farmers to eat sweet potatoes

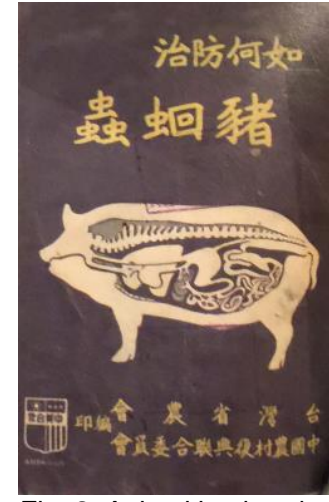

Fig. 3: Animal husbandry handbook

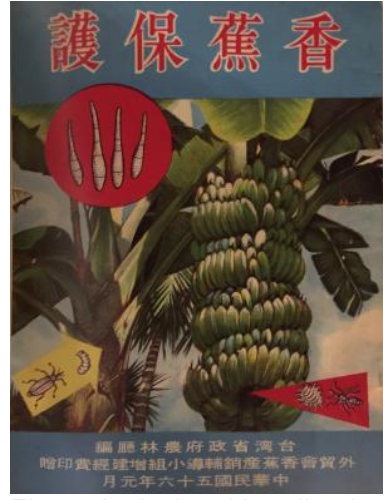

Fig. 4: Agricultural handbook

\section{Agricultural public announcements and graphic design}

The period of U.S. aid was one in which the people followed the example of their leaders. The JCRR shouldered the responsibility for the publicity and promotion of agricultural policy, and promoters were often seen in rural villages carrying canvas work bags on their back to visit many households and deliver illustrated magazines. The propaganda posters the JCRR hung, with content as enriching as a small school booklet, were printed by the JCRR and, because the cost of printing was born by U.S. aid, the "Sino-US Cooperation" logo was printed in the lower right-hand corner. Publicity themes in these posters included informational illustrations on animal husbandry, as in Figure 1: "Will a lack of potash lead to lower rice production?" The poster heading was reminiscent of a course title, and the course content, "getting the fertilizer, fertilizing, harvesting," utilizes four-framed color cartoons with illustrations which were exquisite and provided great detail: an American steamboat has traveled from afar with the imprinted "Sino-US Cooperation" logo carrying fertilizer to Taiwan; farmers accept the fertilizer from the JCRR, and open the bag of potash with an imprinted "Sino-US Cooperation" logo to mix with soil; the self-tilling farmer who had used the fertilizer is then shown smiling after a bountiful harvest. The simple four-frame illustrations could more easily tell the story with greater details, and this was the irreplaceable language of images. In addition, posters were also used as "diagrams for the land reform the government decreed and advocated in order to convey difficult to understand and complicated proclamations, such as when the government encouraged "everyone to eat sweet potatoes" during difficult times in the agricultural period (Figure 2). Promotions became effective through the use of explanatory illustrations. During this period magazine supplements often provided common knowledge and information, and used images to convey ubiquitous common sense learning topics. Examples included household subjects, such as how to knead dough. In 
addition, recipes were illustrated via graphic method. Other issues that were addressed included how to plant a home garden to beautify your life, how to utilize a tiller, the order for dealing with insect stings, rabid dog bites, food poisoning, electrical fires, and others. There was practically no topic these illustrations did not deal with. What is more, the cover in Figure 3 presents the internal structure of a pig through medical anatomical method in order to explain how to prevent Ascariosis. The relationship between pests and plants is illustrated in a scientific diagram to educate farmers on the cover of Figure 4.

\section{Conclusion}

Taiwanese society sought development under Sino-U.S. economic and military cooperation during the period of U.S. aid. During this period, the people became accustomed to relying on flipcharts as an educational method (looking at images to gain knowledge). These posters were loaded with information and used for agricultural advocacy and classroom learning as a result of the driving force of vigorous agricultural promotion. Promotion through educational posters primarily took the form of single color cartoon strips, as well as exquisite and beautiful illustrations. In addition, the influence of American trends could be seen in the American-style advertising for popular agricultural products, as Taiwanese agricultural advertisements used anthropomorphized cartoon images.

\section{References}

Yuan, Y. S. (1998) The Taiwanese economy prior to and after retrocession. Taipei: Linking Publishing. Huang, C. J. (1991) Records of Sino-American Joint Commission on Rural Reconstruction. Taipei: San Min Book co..

Taiwan Provincial Government, Department of Accounting and Statistics (1971) Summary of statistics for Taiwan Province. Nantou County: Nantou Chung-hsing New Village.

Liu, Z. W. (2012) Anecdotes of unforgettable moments in US aid to Taiwan. Taipei: AND Books.

Lai, Y. Z. (1993) Research on the development of Taiwanese periodicals from the Japanese colonial period to 1992. National Chengchi University Graduate School of Journalism M.A. Thesis.

Han, S. H. (2006) Land Reform from 1949 to 1953. Taichung: Shakespeare Cultural Publications.

Tsai, S. S. (2015) The Peasant Movement And Land Reform In Taiwan, 1924-1951. U. S.: Merwinasia.

\section{Biographical note}

Dr. Chu-Yu Sun is currently teaching in the Department of Fine Arts, National Kaohsiung Normal University. Her field of interests covers the research and creation of contemporary New Media Art and Technical Art. Armed with Ph.D. of the History of Design, she continues her research on the History of Art Design and Visual Culture. Meanwhile, she also conducted interdisciplinary research, offering courses concerning performing arts, costume design, audience psychology, semiology, etc. 